\title{
The role of phenomenal displacement on the perception of the visual upright
}

LEONARD BROSGOLE AND ROBERT M. CRISTAL ${ }^{1}$

NAVAL TRAINING DEVICE CENTER
Tilt invariably involves the factor of displacement. A clockwise rotation of a rod, for example, results in the top being displaced to the right and the bottom to the left. The question was raised as to which is primary, displacement or tilt. Through a series of experiments, apparent tilt was found to be the perceptual outcome of phenomenal displacement. In addition, gravity seemed to play no significant role in determining the visual upright. Therefore, the conventionally accepted field theory of apparent verticality was rejected and the visual upright was interpreted according to principles which govern the perception of motion and radial direction.

Man structures his world according to a bodily coordinate system which enables him to assign a position or direction to targets in external space. Accordingly, the midline of the body separates right from left and the eye level position divides up and down. As opposed to being Euclidean or isotropic, visual space is anisotropic. That is to say, the quadrants of visual space created by the bodily coordinates do not possess equal properties or valences and, in this regard, visual experience does not parallel events in the real world. So, for example, of two objects moving at equal speeds, one vertically and one horizontally, the vertically moving object seems to travel about $30 \%$ faster (Koffka, 1935). In the same fashion, an object moving to the right seems to travel more quickly than one displacing to the left at the same velocity (Gemelli, 1958). Although many examples can be given, the important point to remember is that visual space is anisotropic in character; for this feature will be of some importance at a later point in this paper.

In a recent article, Brosgole (1966a) discussed the factors involved in determining perceived direction with specific reference to the straight ahead location in space.

Physiologically determining factors were noted, namely, the region of retinal excitation in conjunction with eye and head position as well as the factor of visual symmetry (i.e., the tendency for the apparent straight ahead to be localized at the center of visual stimulation) which has been termed the Roelofs effect. It was shown that when the two factors were teased apart and thrown into conflict, by presenting a luminous frame in total darkness with its center shifted either $12^{\circ}$ off to the left or right, the situation was resolved by a compromise where the subjective straight ahead displaced toward the center of the visual frame but only by a maximum of $9^{\circ}$.
Visual anisotropy was also found to affect perceived direction; a frame to the right creating a 50\% greater displacement of the subjective straight ahead than one to the left and a frame below eye level generating a far greater effect than one above eye level. Although these findings and principles have been applied to the perception of motion (Brosgole, $1966 \mathrm{a}, \mathrm{b}, 1967 \mathrm{a})$, the question arises as to whether they are also involved in the perception of the visual upright direction in space.

The two factor theory of the perception of the upright initially proposed by Asch and Witkin $(1948 \mathrm{a}, \mathrm{b})$ and Witkin and Asch (1948a, b) and elaborated upon by Witkin $(1950,1952,1965)$ and Wapner and Witkin (1950) has become conventionally accepted. It has been contended, on the one hand, that since the main axis of the body, when in a vertical orientation, is parallel to the walls of buildings and perpendicular to the ground, the surround comes to provide the figural characteristics which contribute to a sense of verticality. On the other hand, the upright position is also determined by the force of gravity which acts upon the skeletal muscles of the body as well as its vestibular network. Although these different sets of cues usually cooperate, they allegedly have been experimentally separated and thrown into conflict. This has been accomplished in one kind of experimental situation by enclosing a vertical luminous rod, in total darkness, within a luminescent frame placed at an oblique orientation-let us say $15^{\circ}$ counterclockwise (CCW). In this instance, where the gravitational upright is no longer parallel to the boundaries of the visual background, the luminous rod appears tilted in a direction opposite to the frame. When required to adjust the rod so that it is vertical, Ss typically rotate it to a $5^{\circ} \mathrm{CCW}$ position. This compromise has been used in evidence favoring the hypothesis that the visual and gravitational cues to verticality combine so as to yield a change in the felt orientation of the body. This change in felt body position, in turn, gives rise to a modified conception of visual space as reflected in the rod and frame task.

This type of analysis seems inadequate for several reasons. For one, if performance on the rod and frame were truly a compromise between postural and visual cues, the effect of the tilting frame should be sensed kinesthetically as well as visually. Just as Brosgole (1966a) pointed out, whenever an asymmetrically extending field effected a shift in the apparent median plane, $S$ felt that his eyes were turned in a direction opposite to the frame as he 
fixated objectively straight ahead. In the same fashion, an objectively upright observer should feel that he is tilted in a direction opposite to the obliquely oriented frame in the rod and frame situation. Yet this is rarely, if ever, the case. The effect, then, seems to be purely visual.

Secondly, although gravity provides information as to the position of the body in space, it tells us nothing of the orientation of the visual target which is, of course, external to the body and hence not sensed posturally. The problem of how we are able to align this target with either the vertical or the midline of the trunk has been basically ignored and, therefore, still remains open.

Finally, instead of assuming that the visual cues to orientation must act through the postural senses in order to generate a change in the directional properties of visual space, it seems far more parsimonious to view the rod and frame as a figural effect which, in turn, may produce a change in the body percept. The following represents an initial step in the logical development of a purely visual analysis of the perception of the upright.

The question may be raised as to whether tilt is a primary perception or if it is the outcome of phenomenal displacement. To be more precise, while the top of a rod at a $15^{\circ} \mathrm{CCW}$ tilt is displaced relatively to the left of the midline of the body, the bottom of the rod is displaced to the right. Do we see this displacement because the rod appears tilted, or is the experienced tilt due to the perceived displacement?

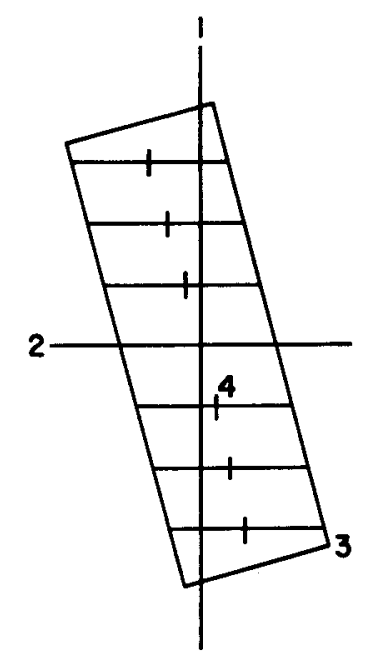

I. OBJECTIVE MEDIAN PLANe

2. EYE LEVEL POSITION

3. FIELD TILTED CCW BY $15^{\circ}$

4. CROSSHATCHES DENOTE THE CENTER OF VISUAL STIMULATION

Fig. 1. Illustrative example of how a rotated field laterally shifts the center of visual stimulation relative to the medial axis of the body.
In the same fashion, when a frame is tilted $15^{\circ}$ $\mathrm{CCW}$, there is a loading of visual stimulation in the upper left and lower right quadrants of space (see Fig. 1). It was reasoned then, according to Roelofs' principle of visual symmetry, that the upper portion of the frame should pull the straight ahead to the left and the lower portion to the right in order for the apparent median plane to be centered laterally within the visual field. The subjective straight ahead, therefore, would assume a CCW orientation but at some intermediate position in objective space. This is because the previously specified physiological determinants of perceived direction would tend to offset the Roelofs effect. A truly vertical rod, then, would have to appear to be tilted clockwise (CW) since, by definition, all points along the vertical are either straight ahead or parallel to the mid sagittal plane. The same analysis applies to a $\mathrm{CW}$ oriented frame.

The following experiments were designed to test the premise that apparent tilt is the outcome of perceived displacement as well as to assess the role of gravity in the perception of the upright.

\section{EXPERIMENT I}

The first study was directed at separating the variables of displacement and tilt. It is possible to represent tilt in a manner other than merely rotating a background. For example, a vertically oriented field can be divided into segments (e.g., upper, middle, and lower) with one aligned directly above the other. Accordingly, shifting the upper segment or frame to the left relative to center and the lower to the right would portray a CCW tilt. Displacing the upper section relatively to the right and the lower one to the left would simulate a CW orientation.

Although the boundaries of each individual frame may remain upright, the main axis of the field appears rotated as a whole when the three are positioned so as to depict a tilt. That is to say, only an obliquely oriented line could join the midpoints of the three frames. In order to change the position of the segments without introducing the feature of tilt, it becomes necessary to randomly present them, one at a time, in temporal succession. The problem now arises as to how far the top and bottom sections must be displaced from center in order to simulate the effect of a field rotated to a designated angular extentlet us say $15^{\circ} \mathrm{CW}$ or CCW. Very specific illustrative examples must be given in order to understand how this dilemma was ultimately resolved.

Let us assume that an 18-1/4 in. vertical rod represented by three discrete points (top, middle, and bottom), as opposed to a continuous line, is centered within a frame placed at a $15^{\circ}$ tilt. How far laterally is the main axis of the frame from each of the points?

Given both the distance between the points and the tilt of the frame, the end points are found to lie 
2-7/16 in. from the midline of the frame by means of simple trigonometrics. The middle point continues to reside along the main axis, because it coincides with the center of rotation. In other words, as a frame is set at a $15^{\circ} \mathrm{CCW}$ tilt, the center of visual stimulation about the upper tip of the vertical rod displaces horizontally by $2-7 / 16$ in. to the left. Similarly, it shifts by $2-7 / 16$ in. to the right of the lower end. In each instance the middle of the rod remains centrally located.

To return to the problem of our segmented frame, then, it is obvious that the central portion must be kept fixed with the upper and lower sections shifted by $2-7 / 16 \mathrm{in}$. in opposite directions so as to duplicate the position changes generated by rotating a field $15^{\circ}$ about a rod of the specified length. Since this study will be concerned with the effect of successively repositioning the upper and lower segments upon the apparent median plane, the middle frame was placed objectively straight ahead of the observer.

Having reviewed the underlying logic of this experiment, we may at long last reveal its precise intent, namely, to present $S$ with a given segment of the frame and a point located within it over a series of trials. In other words, on one trial $S$ may see a point surrounded by the upper frame displaced to the left; on the next trial a point within the central section; on the following trial the bottom segment to the right with its associated point, etc. With the points separated vertically by 9.12 in., $S$ would be required to adjust them to the subjective straight ahead location. Should the asymmetrically positioned upper and lower sections generate a Roelofs effect, then, a CCW tilt would result when joining the points associated with the upper left, center, and lower right frames. In the same fashion connecting the points related to the upper right, center, and lower left sections would yield a CW tilt. The purpose of this study, therefore, was to determine the relationship between the data obtained under this procedure with those yielded in the typical rod and frame situation.

\section{Method}

Apparatus. A piece of equipment was fabricated to simulate the position changes produced by a tilting frame. A $4 \mathrm{sq}$. ft. wooden panel was fastened flat against one of the walls of the laboratory (see Fig. 2). Three pairs of collars were affixed to the board, in rows, to serve as sleeves accommodating three horizontally sliding bars. Two vertically hanging wooden strips, separated by 28 in., were attached to each of the bars. The six strips (two on top, two in the center, and two on the bottom) produced the base upon which the fragmented frame was mounted. The frame will be described in detail at a later point.

Two vertical shafts, $3 \mathrm{ft}$. in length, were fastened to the wooden mounting board, one to the extreme left side and one to the extreme right. Three pulleys

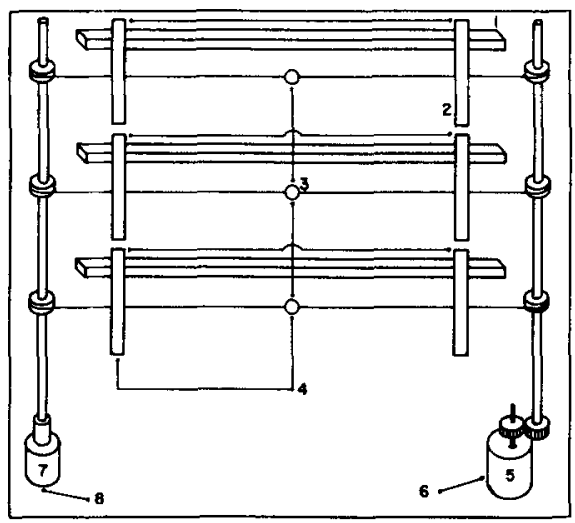

1. ONE OF THREE SLIOING QARS . UPPER RIGHT FRAGMENT OF FRAME

5. SELSYNS MOTOR (SLAVE UNIT ) 6. TO SUBJECT'S CONTROL UNIT

4O SELECTOR SWITCHES Q TRANSFORMER B. TO RECORDING SYSTEM

Fig. 2. Schematic representation of the displacement apparatus.

were secured to each shaft so as to constitute three separate sets going horizontally. Each set was joined by a horizontal belt. The three points denoting a rod were hooked onto the belts, i.e., one on each belt.

The frame consisted of two vertical borders fragmented into three segments: upper, middle, and lower. There were no horizontal contours present. Because the experiment took place in total darkness, the frame was constructed of Sylvania, white, electroluminescent Tape Lite. Essentially, the Tape Lite consists of heavy gauge aluminum foil strips coated with a phosphorescent paint and laminated in a flexible plastic casing. The phosphors glow in darkness when electrically excited. The Tape Lite provided the capability of switching the three segments on and off individually, or in combination, at any desired brightness. The Tape Lite was mounted on the wooden strips which hung vertically from the sliding bars. The borders of the frame were $1 \mathrm{in}$. wide. They were separated by $28 \mathrm{in.,}$ or $30 \mathrm{in}$. from the outside of one to the outside of the other. Each segment was 9 in. long with a $1 / 8$ in. separation between segments. The total frame was, therefore, 27-1/4 in. long. The two borders comprising a section were wired in series with the three. sections feeding in parallel through a selector switch to an ac variable transformer used to control their brightness. The frame was set at .1 ft. $-\mathrm{L}$.

The rod was composed of three circular spots of light, 3/16 in. in diameter. They, too, were made of Tape Lite and wired in parallel to a selector switch which permitted them to be turned on in any combination. The switch was connected to a variable transformer which was used to set the dots at .1 ft.-L. The middle dot was centered vertically within the frame. The top and bottom points were aligned $9-1 / 8$ in. above and below the middle one. In other words, each dot was centered vertically within its given frame.

The middle frame was fixed in S's objective median plane with its vertical center 38 in. above the floor. 
The position of the top and bottom frames was varied by $2-7 / 16$ in. to the right or left of center in order to simulate a $15^{\circ}$ tilt. The location of the dots was controlled by $S$. Because of the design of the equipment, all three points moved at once. This did not matter, of course, since $S$ saw only one spot at a time surrounded by a given frame.

The $S$ was able to vary the position of the dots by means of a Selsyns synchronous motor connected to a mate which was geared to one of the vertical shafts on the mounting board. Thus, as $\mathrm{S}$ rotated a circular control knob, the connected shaft and pulleys rotated, moving the belts and points and causing the other vertical shaft to spin. This shaft was geared to a 10-turn linear potentiometer which rotated along with it. With a dc voltage placed across the coil of the potentiometer and leads feeding from one terminal and the armature through a Brush high gain amplifier to a Brush strip chart recorder, S's adjustments were translated into voltage outputs and, thereby, concurrently charted. The gearing arrangements were such that within 10 turns of the control knob S was able to move the spots $12 \mathrm{in}$. across space, 6 in. to the right or left of center. His adjustments were permanently recorded. The data obtained in this displacement condition were compared to those gathered in a rod and frame situation. This, of course, necessitated the building of a rod and frame apparatus.

The rod and frame device was identical in all essential details to the displacement apparatus, except that all three segments and points were simultaneously visible. Instead of displacing, as before, they now rotated about the middle point of the rod. While $E$ controlled the tilt of both the rod and frame, $S$ remotely varied only the orientation of the rod by means of a DPDT momentary toggle switch. The S's responses were recorded directly from a protractor located behind the frame.

Procedure. The S viewed the displacement apparatus from a distance of $6 \mathrm{ft}$. in total darkness with his head in a Bausch \& Lomb chin rest. The $S$ was told that he would see a luminous frame, which may be placed in various positions over a series of trials, and a spot of light within the frame. He was advised to ignore the frame and attempt to place the point directly straight ahead (i.e., between his two eyes or perpendicular to the midline of his body) by turning the control knob appropriately.

The frames were presented in three different sequences. They were: (a) upper frame to the left, middle one centered, and lower one to the right; (b) upper to the right, middle one centered, and lower to the left; and (c) upper, center, and lower sections aligned vertically. The position of the segments were randomized within each sequence and the sequences counterbalanced among Ss. The starting position of the dots, either $2-7 / 16$ in. to the left or right, was counterbalanced over trials in an ABBA fashion.
The $\mathrm{S}$ closed his eyes between presentations. There were 36 trials in total, each frame appearing in a given location on four occasions.

In a second condition, $\mathrm{S}$ was rotated by $180^{\circ}$ so as to face the rod and frame device. He viewed it through a Bausch \& Lomb chin rest from a distance of $6 \mathrm{ft}$. The frame was set at either a $15^{\circ} \mathrm{CW}, \mathrm{CCW}$, or vertical orientation and the rod placed at either a $15^{\circ} \mathrm{CW}$ or $\mathrm{CCW}$ tilt. The orientation of the frame was randomized for each $S$ and the starting position of the rod counterbalanced over trials. There were 12 trials with the frame appearing four times at each setting. The $\mathbf{S}$ was instructed to ignore the frame and rotate the rod to an upright position, i.e., running straight up and down from head to foot or parallel to the medial axis of his body. Half of the Ss were exposed to Condition 1 first while the other half started with Condition 2.

Subjects. Four males and eight females participated in this study. Ranging in age from 17-23, their mean age was 19.3 years. They were undergraduate students from C. W. Post College who were naive as to the purpose of the experiment.

\section{Results and Discussion}

The displacement data obtained in the first condition was transformed into tilt scores, joining the three points in sequence " $a$ " yielding a CCW tilt and in " $\mathrm{b}$ " a CW tilt. The S's constant error was calculated for both " $a$ " and " $b$ " and the distance between them represented a range of error produced by the two different treatments.

An error range of $20.25^{\circ}$ was found for Condition 1 as compared to $9.67^{\circ}$ for Condition 2. Although the two conditions were significantly correlated $\left(r_{S}=+.54\right.$, $p<.05)$, they also differed from one another reliably according to the Wilcoxon Signed-Ranks Test $(T=0$, $\mathrm{N}=12, \mathrm{p}<.01$ ).

The significantly high correlation between the two sets of data tended to break down upon closer scrutiny, i.e., when comparing a given treatment in one condition to its counterpart in the other. Thus, the mean of the deviations from the apparent upright generated by the simulated $\mathrm{CCW}$ tilt of the frame (the difference between treatments " $a$ " and " $c$ ") did not significantly correlate with the corresponding errors found in the actual rod and frame condition $\left(r_{s}=+.24\right)$. The CW errors for the two conditions were also not significantly related $\left(\mathrm{r}_{\mathrm{S}}=+.44\right)$.

One may attempt to conclude at this point that apparent tilt is in no way the perceptual outcome of phenomenal displacement, that the two factors are related only in a gross sense, possibly through a mutual association with some other unknown variable. Our vast experience with the Roelofs phenomenon, however, tends to indicate that the displacement condition yielded too great an effect. In addition, examination of the raw data showed S's performance to be 
extremely erratic-a rather unusual finding. In other words, some factor seemed to be operating in the displacement condition which has not been given prior consideration. The following study, therefore, was aimed at determining precisely what was disrupting performance and inflating the Roelofs effect.

\section{EXPERIMENT II}

In a previous study, Brosgole (1966a) attempted to relate the Roelofs effect to induced motion. In one condition, a luminous point was surrounded by a frame in total darkness and the frame was discretely placed in 13 different locations, over a series of trials, ranging from $12^{\circ}$ to the left to $12^{\circ}$ to the right of the objective median plane. The $S^{\prime}$ 's task was to adjust the point to the straight ahead for each position of the frame. It was found that as the background was displaced laterally, progressing from one position to the next in a continuous fashion, the apparent straight-ahead tended to track along with the frame, lying midway between its center and the objective median plane. In some pilot research, however, the frame was randomly placed in one of the 13 locations in a given trial. This gave rise to some quite unpredictable behavior. For example, Ss tended to offer an abundance of extreme responses, i.e., a $12^{\circ}$ shift of the frame often resulted in a $20^{\circ}$ displacement of the apparent median plane. In addition, responses were highly variable. After a while, the relationship between the position of the field and the apparent median plane completely dissipated for many Ss. It was as if $S$ just did not know where to locate the visual straight-ahead and was wildly guessing.

This same type of behavior was observed in the displacement condition of Experiment $I$. The displacement apparatus was designed to provide a stop, preventing the points from being moved more than 6 in. off center. Several Ss had to be rejected for attempting to smash the points beyond the stop. In fact, we adopted the criterion of rejecting any $S$ who tended to jeopardize the equipment.

It was reasoned that perhaps this kind of performance was initiated by randomly presenting the frames within a given sequence. The feature of continuity, therefore, was added to the displacement task. Just as in the rod and frame situation where $S$ has the freedom to repeatedly scan up and down from one end of the rod to the other, prior to each judgment, we decided to alternate between the top and bottom sections of the fragmented frame within a given treatment so as to provide some semblance of order. The middle point and segment was occluded in both conditions to simplify the procedure, since they did not furnish much additional information.

\section{Method}

Apparatus. The center point and segment was omitted from the displacement apparatus as well as the rod and frame device. Everything else remained unchanged.

Procedure. Only the top and bottom frames were displayed in each treatment within the displacement condition. They were presented in a regular fashion so that an upper frame was followed by a lower section which was then followed by an upper one, etc. At least $90 \mathrm{sec}^{2}$ were permitted to elapse before going from one trial to the next in order to allow any Roelofs effect genexated during a given trial to dissipate as well as to prevent $\mathrm{S}$ from gaining the impression of field tilt. The three sequences previously employed were again counterbalanced among Ss. At times the top segment was the first to be presented within a given treatment and at other times the bottom section was initially exposed. A given frame appeared four times in each of its positions, making a total of 24 trials.

The balance of the procedure was identical to the first experiment.

Subjects. Five males and five females participated in this study. Ranging in age from 18 to 24 , their mean age was 19.8 years. They were undergraduates from C. W. Post College who were naive as to the purpose of the experiment.

\section{Results and Discussion}

The displacement condition yielded a mean error range of $12.6^{\circ}$ compared to $12.5^{\circ}$ for the rod and frame condition. The two sets of data were significantly correlated $\left(r_{\mathrm{s}}=+.88, \mathrm{p}<.01\right)$ and not reliably different according to the Wilcoxon Test $(T=27.5$, $\mathrm{N}=10$ ) .

In addition, the tilt derived from the displacement data now conformed internally to that obtained in the rod and frame situation. The CCW deviations from the apparent upright were significantly correlated $\left(\mathbf{r}_{\mathrm{S}}=\right.$ $+.75, p<.01)$ as well as the CW errors $\left(r_{S}=+.57\right.$, $\mathrm{p}<.05$ )

It appears, then, that the randomization procedure used in the first experiment seriously disrupted performance in the displacement condition. We may, therefore, conclude that apparent tilt seems to be the outcome of perceived displacement. The following studies are directed at critically testing several corollaries of this proposition.

\section{EXPERIMENT III}

A very curious effect was observed in the laboratory. If half of a rod is occluded after the whole rod has been adjusted to the apparent upright within a tilted frame, the remaining half seems to change its orientation. The bottom half usually appears to be tilted too little and the upper half too much. Actually this effect is not so surprising when taking into account our earlier discussion of visual anisotropy.

To be more precise, Brosgole (1966a) found that 
when two asymmetrically positioned frames are simultaneously presented, one above the other, the lower frame tends to dominate in determining the egocentric straight ahead as represented by a single point. Similarly, a rotated frame may be conceived of as two, simultaneously presented, asymmetrically extending fields with the upper half shifted in one direction and the lower half in the other. Accordingly, the bottom half should generate more of a Roelofs effect than the top half. Therefore, when successively adjusting two rods to the apparent upright, one extending from the center of the tilted frame upward and the other from center downward, the lower rod should be placed in a more severe orientation. The following experiment was designed to test this proposition.

\section{Method}

Apparatus. Only the rod and frame device was used in this study. The entire frame was exposed and the borders were not segmented. The rod, which consisted of two points, was 9-1/8 in. long.

Procedure. The $\mathrm{S}$ participated in two conditions. The rod extended from the center of the frame upward in one condition and from the center downward in the other. The frame was placed at either a $15^{\circ} \mathrm{CW}$ or $\mathrm{CCW}$ orientation. The position of the frame and placement of the rod was randomized differently for each $S$ with each placement occurring four times for a given treatment, making a total of 16 trials. The starting position of the rod was counterbalanced as in the preceding experiments. The $S$ adjusted the rod to the medial axis of his body from a distance of $6 \mathrm{ft}$. while positioned in the chin rest.

Subjects. Two males and three females served as Ss. They were all 19 year old undergraduate students from C. W. Post College.

\section{Results and Discussion}

The bottom rod was placed at a greater tilt than the top one without exception. This was significant according to the Binomial Test $(X=0, N=5, p<.05)$. There was a mean error of $14.80^{\circ}$ for the bottom rod compared to $10.75^{\circ}$ for the top rod.

It would seem that a mean difference of $4.05^{\circ}$ is far too sizable to be managed by the type of system initially proposed by Asch and Witkin; for according to their thinking, a rotated frame could not possibly generate two different visual upright directions in space which is contingent upon the precise location of the rod within the frame.

To summarize, the best fit for the apparent upright, as generated by a tilting frame, is a bent rather than a straight line. This was repeatedly evidenced in our laboratory. Throughout our research, whenever Ss adjusted the rod so that its bottom half appeared straight up and down, the top portion looked too far off to the side. When rotating it back so as to properly align the top half, the bottom appeared tilted too far over. After a seemingly endless period of aligning and realigning the rod, our Ss typically offered a quite unsatisfactory compromise as their final judgment. We contend that this common experience is the product of visual anisotropy, as opposed to an active competition between the visual and postural cues to the perceived upright.

\section{EXPERIMENT IV}

The question was raised as to what impact a rotated frame would have on the perception of the visual upright if the Roelofs effect were destroyed. This necessitated maintaining the symmetry of the visual field when placing the frame at an oblique orientation. The frame was, therefore, surrounded by a ring which served to keep the visual surround evenly balanced about the medial axis of the body regardless of what tilt the frame was set. In the following experiment, such a condition was compared to one in which the frame was the outer figure enclosing an annulus, thereby, permitting the center of space to shift while holding the numbers of elements in the field constant.

\section{Method}

Apparatus. The equipment consisted of a $28 \mathrm{in}$. square frame enclosing a 9 in. long rod. Both were mounted on a tripod and rotated about the same center which was located straight ahead, 38 in. from the floor. The frame contained two vertical and two horizontal borders which were coated with luminous paint. 3 They were $3 / 4$ in. wide, as was the rod which was also luminous. As $S$ could not remotely control this device, $E$ adjusted the rod with a string and pulley setup. Recordings were made directly from a protractor located on the face of the frame.

Procedure. The $\mathrm{S}$ participated in three conditions. He was presented with the 28 in. square surrounding a 28 in. diameter ring in the first condition. The ring was also luminously painted and its contour was $3 / 4$ in. wide. He again saw the frame in the second condition, but this time it was immediately surrounded by an annulus which was about 39-1/2 in. in diameter. The corners of the frame just touched the surface of the ring. The frame was placed at either a $15^{\circ}$ $\mathrm{CW}, \mathrm{CCW}$, or vertical orientation on four occasions within each condition, making a total of 12 trials. The treatments were randomized differently for each $S$. The $E$ adjusted the rod untll $S$ indicated that it was egocentrically upright. The starting position of the rod $\left(15^{\circ} \mathrm{CW}\right.$ or $\left.\mathrm{CCW}\right)$ was counterbalanced over trials.

In a third or control condition, $S$ instructed $E$ as to how to adjust the rod which was surrounded only by the $39-1 / 2$ in. circle. There were 12 such trials. The three conditions were counterbalanced among Ss. The experiment took place in total darkness with $S$ seated $6 \mathrm{ft}$. from the apparatus.

Subjects. Seven males and three females partici- 
pated in this study. Ranging from 17 to 20 , their mean age was 18.7 years. They were naive Ss from C. W. Post College.

\section{Results and Discussion}

We first sought to determine whether the large ring alone tended to elicit the same type of performance as the upright frames in the other two conditions. The average deviation from the true vertical was calculated, therefore, for the upright treatment of Conditions 1 and 2 as well as for the control. It was found to be $.75^{\circ}, .75^{\circ}$, and $.79^{\circ}$, respectively. These differences were not significant according to the Friedman Two Way Analysis of Variance $\left(\mathrm{Xr}^{2}=\right.$ .45 , $\mathrm{df}=2, \mathrm{p}=.80$ ). This permitted us to utilize the control as a standard for evaluating the effects of rotating the visual field.

Tilting the frame in the first condition yielded an average deviation of $2.85^{\circ}$ compared to $1.01^{\circ}$ in the second condition and, as indicated above, $.79^{\circ}$ in the control. These differences were significant beyond the $1 \%$ confidence level $\left(\mathrm{Xr}^{2}=15.45, \mathrm{df}=2, \mathrm{p}<.001\right)$. While Condition 1 differed reliably from 2 and 3 according to the Wilcoxon Test (in both instances $T=0, N=10$, $\mathrm{p}<.01$ ), the latter two were essentially the same $(\mathrm{T}=18, \mathrm{n}=10)$.

Our results clearly indicate that maintaining the symmetry of visual space completely nullifies whatever influence a rotated frame may have upon the perception of the upright. These findings cannot be understood in terms of an Asch-Witkin type of hypothesis, because surrounding a frame with an annulus (as in Condition 2) in no way changes the main axis of the field as a whole. In other words, as the frame is rotated in a given direction, its orientation is rather conspicuous and should, therefore, compete with the force of gravity in determining the visually perceived upright. Yet the field had no effect. Accordingly, we may conclude that apparent tilt is the perceptual outcome of phenomenal displacement.

\section{EXPERIMENT V}

The question arises as to whether neutralizing gravity would have an effect upon the perception of the visual upright. A rod and frame study was, therefore, devised in which gravity was made incidental to the performance of the task.

\section{Method}

Apparatus. The rod and frame device employed in the last experiment was again used, except that the 9 in. rod was now surrounded by the $28 \mathrm{in}$. square frame with no circles present.

Procedure. In the first condition, $\mathrm{S}$ was seated at a distance of $3 \mathrm{ft}$. from the apparatus. His head was fixed in a chin rest with the eye level position 44 in. above the floor. The center of the rod was 38 in. above the floor or 6 in. below eye level. The frame was presented at either a $15^{\circ} \mathrm{CW}, \mathrm{CCW}$, or vertical orientation with each treatment repeated four times, in randomized order, making a total of 12 trials. Just as before, $E$ adjusted the rod until $S$ indicated that it was coincident with the medial axis of his body. The starting position of the rod was counterbalanced over trials.

The second condition was designed to neutralize the force of gravity. Exactly the same procedure was followed as in Condition 1, except that $S$ was placed in a supine position with the rod and frame over head. Essentially, the apparatus was removed from its tripod and clamped to a wall so that it extended horizontally outward with the surface of the frame parallel to the floor and ceiling and, hence, S's body. The S gazed upward at the device from a distance of $3 \mathrm{ft}$. The mid sagittal plane of his body coincided with the main line of the frame when placed at a zero setting. The center of the rod was 6 in. below eye level. Through this method, S's estimation of the visual upright was purely on a head-foot basis, i.e., postural cues to verticality could not have possibly been used. The order of presenting the two conditions was counterbalanced over Ss.

Subjects. Five males and five females served as Ss. They ranged in age from 17 to 37 , with a mean of 24.8 years. All were naive as to the purpose of this experiment.

\section{Results and Discussion}

Condition 1 yielded a mean error range of $13.9^{\circ}$ compared to $19.4^{\circ}$ for the second or reclining condition. This difference was not significant according to the Wilcoxon Test $(\mathrm{T}=11, \mathrm{~N}=10) .4$ Yet it cannot be denied that placing $S$ in a supine position did yield a substantial difference. For example, six Ss displayed a greater error in Condition 2, two in Condition 1 , and two showed no difference. The question arises as to why a greater accuracy in performance was associated with an erect postural orientation.

It is difficult to resolve this matter through a literature search, because the data from the various experiments dealing with body tilt have been expressed in different terms, i.e., average deviations, constant errors and points of subjective equality. Although it is impossible to compare one experiment to another, one fact clearly stands out, namely, performaince deteriorates, whenever $S$ is tilted. This seems to hold whether the tilt conflicts with gravity as in the case of Witkin and Asch (1948a) and Bauermeister (1964) or gravity is neutrallzed as in the case of Rock (1954) who used a procedure similar to our own. It seems as if merely forcing $S$ to function in a unique or unfamiliar orientation disrupts the accuracy of his responses.

Phenomenological data seem to indicate that Ss do not employ gravitational cues in judging the visual upright. They show no difficulty, for example, when 
instructed to adjust a rod to the vertical direction from a standing position, even though it is placed either flat upon the floor or against the ceiling. In other words, the concept of verticality appears to have an egocentric reference as opposed to an external one. In addition, most Ss verbally respond to tilt in displacement terminology. They tend to judge a rod as tilted to the right or left, because such concepts expressing rotation as CW and CCW simply are not high within their repertoire. This mode of responding led to some confusion in Experiments 4 and 5, because $\mathrm{E}$ would have to determine which half of the rod $S$ was referencing (i.e.o top or bottom) when indicating that it required either a left or right adjustment. This drove us to developing the semi-automatic rod and frame device described in the earlier studies.

Both the empirical and phenomenological findings lend to the conclusion that the force of gravity does not significantly contribute to the perception of the visual upright.

\section{EXPERIMENT VI}

In this final study, induced motion was utilized as a technique for separating the factors of displacement and tilt. A point surrounded by a vertically moving frame is usually seen to move up and down in a direction opposite to the true motion of the frame. Placing the frame at a tilt results in an apparent diagonal movement of the point. In other words, the phenomenal upright changes by merely rotating the vertically traveling surround. The slope of the point's subjective motion can be ascertained by requiring $S$ to adjust it from left to right so that it appears to journey straight up and down. For example, a target seen to move down and to the left would be adjusted to the right in order to restrict its motion to the phenomenally vertical direction of space. The amount of lateral displacement imposed upon the point can then be taken in conjunction with the extent of the frame's vertical travel to yield the angle at which the target appears to move.

Placing a reduction screen with a thin horizontal aperture directly in front of the frame removes the feature of tilt from the situation. Since horizontally orienting the aperture occludes everything but a small portion of the left and right borders of the tilted field, the vertical motion of the frame is visually destroyed. Instead of appearing to move up and down, the two slanted borders surrounding the target are seen to slide back and forth laterally. The Roelofs effect generated by the vertically displacing frame can thereby be assessed by requiring $S$ to continuously adjust the target to the apparent straight ahead location. The amount of displacement imposed upon the target $_{v}$ resulting from this procedure, may then be translated into tilt data in the aforementioned manner.

\section{Method}

Apparatus. The apparatus used has been described elsewhere in greater detail (Brosgole, 1967a). It basically consisted of a wooden screen, upon which stimuli could be mounted, driven by a motor via a system of gears and pulleys so as to travel up and down vertically. The spatial position of the screen, at any given point in time, was transmitted electronically and plotted on a Brush strip chart recorder. There were also provisions for a target which $S$ could remotely adjust from left to right by rotating a circum lar knob fixed to the shaft of a Selsyns motor. Its spatial location was also recorded on the Brush.

A 28 in. square frame, constructed of 1 in. wide Tape Lite, was fastened to the screen at a $15^{\circ} \mathrm{CCW}$ tilt. The Tape Lite was also used for making a circular target, 3/16 in. in diameter.

The frame moved up and down, over a distance of 18-1/4 in., at a rate of $40 \mathrm{~min}$. of visual arc per sec. Its brightness was set at $.1 \mathrm{ft} .-\mathrm{L}$ compared to 1.8 ft. $-\mathrm{L}$ for the target.

Procedure. The experiment took place in total darkness with $S$ positioned in a chin rest at a distance of $12 \mathrm{ft}$. from the apparatus. The frame's center of rotation, as well as the target, was in the objective median plane, 38 in. above the floor.

The frame moved up and down vertically in the first condition with the target initially positioned in the objective median plane. As the frame moved, $S$ adjusted the target laterally so as to cancel out any apparent diagonal motion, i.e., $S$ restricted the movement induced in the target to the subjective vertical axis of space. His adjustments were recorded for three complete cycles of the frame.

In the second condition, a reduction screen with a $1-1 / 2$ in. wide horizontal aperture was placed directly in front of the frame. The aperture extended $3 / 4$ in. above and below the center of the target. Only a small fragment of the left and right borders of the frame was seen through this opening. The $S$ placed the target in the apparent median plane with the field centered vertically. He attempted to keep it phenomenally straight ahead. When the frame was set into motion, its borders displaced back and forth laterally, inducing a horizontal movement in the target. The frame was again permitted to go through three full up and down excursions while $S$ 's responses were being recorded. The two conditions were counterbalanced over Ss.

Subjects. Four females, ranging in age from 22 to 30, participated in this experiment. Their mean age was 26.0 years. They were naive as to the purpose of this study.

\section{Results and Discussion}

In both conditions, the position of the target was obtained and averaged for the three times that the frame was at its upper as well as its lower extreme. The difference between the two means served to indicate the total extent to which $\mathbf{S}$ displaced the target in each condition. 
Converting the displacement data into angular terms, the tilting frame caused the apparent upright to deviate $\mathrm{CCW}$ from the true vertical by an average of $6.9 \circ$, whereas the deviation generated by the Roelofs effect was $7.2^{\circ}$. One $S$ was in greater error in the first condition, two in the second, and one performed equally as well in both.

The implications of this study, insofar as it relates to the perception of motion, will be discussed in far greater detail in the following section. However, we may conclude, at this point, that a rotated field affects the visually perceived upright only by virtue of the Roelofs phenomenon.

\section{Further Considerations}

Our system of thinking may be used to account for some commonly observed but yet unexplained phenomena. For one, there seems to be a greater degree of accuracy associated with adjusting a long rod to the visual upright, in total darkness, compared to a shorter one. This is quite understandable if tilt is viewed as the product of displacement, for lengthening a rod increases the lateral divergence of its end points with tilt held constant. Since the horizontal discrepancy between the ends of a long rod is far more noticeable, the rod is rotated back toward the true vertical resulting in a higher proficiency of performance.

Working with induced movement, Brosgole (1967b) noticed that when a frame is asymmetrically positioned beyond a certain critical limit, the Roelofs effect begins to degenerate. Accordingly, an objectively stationary target was induced to move in a direction opposite to the true motion of its surround until a given point when it reversed direction and journeyed along with its background. This finding has implications for performance on the rod and frame, namely, placing the frame at a severe enough tilt should cause the Roelofs effect, and hence and frame's influence upon the rod, to dissipate. This is actually observed to occur.

The foregoing probably applies to problems of visual adaptation to displacement and tilt. That is to say, we suspect that there is an intrinsic relationship between the degree of adaptation and the Roelofs effect, and that adaptation would progressively decrease along with the Roelofs phenomenon beyond a critical point of field displacement or tilt.

Having dispensed with some pragmatic issues, let us embark upon a more profound theoretical analysis of the perception of the upright. Since, by definition, the perception of the upright is the perception of direction, a comprehensive theory of the upright should also apply to the perception of radial direction and movement. We propose that the type of field theory that currently exists, be it one of relational determinism or sensory tonic, is incapable of fulfilling this requirement. The verity of this proposition can be established by means of an example which demonstrates the integral relationship between the upright and radial directions of space.

When a laterally displacing frame surrounds a vertically moving point, the target is seen to move diagonally. Similarly, when two points move downward along a $45^{\circ}$ meridian, so that their paths of motion intersect at a right angle, they are seen to horizontally approach and withdraw from one another. (This type of phenomenon has been demonstrated by Johansson, 1958.) These are cases in which the true vertical and horizontal directions of phenomenal space are markedly altered without rotating a visual surround. They can be explained by the Roelofs effect.

In the first instance, the target seems to travel diagonally because it displaces vertically with regard to the apparent eye level position and laterally with respect to the apparent median plane, which tends to shift to the side with the center of the frame. According$l y$, the resultant motion of the target is along an oblique plane.

In the second case, the two targets are seen to move horizontally because they both approach and withdraw from the apparent median plane. Since the subjective eye level position also tends to be symmetrically located within the field, it shifts up and down so as to be localized between the two points. This cancels out the vertical aspect of the targets' movement, leaving only the horizontal component.

We submit that a theory of the upright must attempt to incorporate these effects since they bear directly upon the upright dimensions of space. Yet it would be most difficult to apply one which is based upon a competition between visual and gravitational cues. In fact it would be absurd.

A theory of spatial orientation must also attempt to deal with the perception of size, i。e., since size is nothing more than the linear extent joining two directions. Although this is a matter for another paper, 5 vertical extensity can be represented in egocentric terms. For example, imagine a vertical line, which extends downward from eye level, traveling away from an observer. Assuming that the apparent eye level position does not change with distance, that line would remain egocentrically located between eye level and the ground or foot level. Its apparent size, therefore, would persist despite its diminishing angular extent. It would be nonsensical even to attempt to apply a theory of direction to this issue which is based upon postural cues.

Field theory has differed from our approach even pragmatically. Sensing a relationship between many phenomena, several workers have run an endless number of correlational studies, attempting to seek out their common elements in terms of the personality dynamics of the individual. We, on the other hand, 
have been task oriented, striving to join several bodies of literature, thereby, gaining an appreciation of perceptual events.

In summary, the visual upright has been placed within the framework of the perception of direction. A purely visual analysis of the upright, derived from the principles of motion and direction perception, was developed as an alternative to field theory.

\section{References}

Asch, S. E., \& Witkin, H. A. Studies in space orientation. I. Per ception of the upright with displaced visual fields. $J$. exp Psychol., 1948a, 38, 325-337.

Asch, S. E., \& Witkin, H. A. Studies in space orientation. II. Perception of the upright with displaced visual fields and with body tilted. J. exp. Psychol., 1948b, 38, 455-477.

Bauermeister, $M$. The effect of body tilt on apparent verticality, apparent body position, and their relation. J. exp. Psychol., $1964,67,142-147$.

Brosgole, L. An analysis of induced motion. Naval Training Device Center, Techn. Rep. IH-48, February, 1966a.

Brosgole, L. Change in phenomenal location and the perception of motion. Percept. mot. Skills, 1966b, 23, 999-1001.

Brosgole, L. Induced autokinesis. Percept. \& Psychophys,., 1967a $2,69-73$.

Brosgole, L. The uniformity of induced movement. Unpublished data on Project No. 7885-8, Naval Training Device Center, $1967 \mathrm{~b}$.

Gemelli, A. The visual perception of movement. Amer. J. Psychol. $1958,71,291-297$.

Johansson, G. Rigidity, stability, and motion in perceptual space. Sweden: University of Upsala, March, 1958

Koffka, K. Principles of gestalt psychology. New York: Harcourt, Brace, 1935 .

Rock, I. The perception of the egocentric orientation of a line. J. exp. Psychol., 1954, 48, 367-374.
Wapner, S., \& Witkin, H. A. The role of visual factors in the maintenance of body-balance. Amer. J. Psychol., 1950, 63, 385-408.

Witkin, H. A. Perception of the upright when the direction of force acting on the body is changed, J. exp. Psychol., 1950, 40, 93106.

Witkin, H. A. Further studies on perception of the upright when the direction of force acting on the body is changed. $J$. exp Psychol., 1952, 43, 9-20.

Witkin, H. A. Development of the body concept and psychological differentiation. In $\mathrm{S}$, Wapner and $\mathrm{H}$. Werner (Eds.), The body percept. New York: Random House, 1965, pp. 26-47.

Witkin, H. A., \& Asch, S. E. Studies in space orientation. III. Perception of the upright in the absence of a visual field. $J$. exp. Psychol., 1948a, 38, 603-614.

Witkin, H. A., \& Asch, S. E. Studies in space orientation. IV. Further experiments on perception of the upright with displaced visual fields. J. exp. Psychol., 1948b, 38, 762-782.

\section{Notes}

1. The authors express their appreciation to $\mathrm{S}$. Jordan for his many helpful suggestions and critical comments throughout the course of this research.

2. Since Brosgole (1967a) has shown that $31 \mathrm{sec}$. is sufficient to permit a Roelofs effect of over $6^{\circ}$ of visual arc to completely diminish, it seemed perfectly reasonable to assume that the after effects of a given trial would most certainly dissipate after $90 \mathrm{sec}$.

3. These experiments were not performed chronologically in the order appearing in this article. Since the Tape Lite has been a relatively recent acquisition, luminous paint was used in constructing stimuli for the earlier studies.

4. Even smaller differences between the two conditions were found when the experiment was replicated with different tilts. Ten degrees of field tilt was used in one instance and $5^{\circ}$ in another. 5. S. Jordan and L. Brosgole have embarked upon a study of the egocentric determination of size perception as part of a joint effort in the Naval Training Device Center.

(Accepted for publication February $15,1967$. 